\title{
Disease association with two Helicobacter pylori duplicate outer membrane protein genes, homB and homA Monica Oleastro ${ }^{1,2}$, Rita Cordeiro ${ }^{1}$, Yoshio Yamaoka ${ }^{3}$, Dulciene Queiroz ${ }^{4}$, Francis Mégraud*2,5, Lurdes Monteiro ${ }^{1}$ and Armelle Ménard2,5
}

\begin{abstract}
Address: ${ }^{1}$ Departamento de Doenças Infecciosas, Instituto Nacional Saúde Dr Ricardo Jorge, Av. Padre Cruz, 1649-016 Lisboa, Portugal, 2 INSERM U853, 33076 Bordeaux, France, ${ }^{3}$ Department of Medicine, Michael E. DeBakey Veterans Affairs Medical Center and Baylor College of Medicine, 2002 Holcombe Blvd., Houston, Texas 77030, USA, 4Laboratório de Pesquisa Bacteriologia, Faculdade de Medicina, UFMG, Av. Alfredo Balena, 190 S/4026 30130-100, Belo Horizonte, Brazil and 5 Université Victor Segalen Bordeaux 2, Laboratoire de Bactériologie, Bat. 2B RDC Zone Nord, 33076 Bordeaux cedex, France

Email: Monica Oleastro - monica.oleastro@insa.min-saude.pt; Rita Cordeiro - rita.cordeiro@insa.min-saude.pt; Yoshio Yamaoka - yyamaoka@bcm.tmc.edu; Dulciene Queiroz - dqueiroz@medicina.ufmg.br; Francis Mégraud* - francis.megraud@chubordeaux.fr; Lurdes Monteiro - m.lurdes.monteiro@insa.min-saude.pt; Armelle Ménard - armelle.menard@labhel.u-bordeaux2.fr

* Corresponding author
\end{abstract}

Published: 22 June 2009

Gut Pathogens 2009, I:12 doi:10.1 186/1757-4749-1-12
Received: 17 April 2009

Accepted: 22 June 2009

This article is available from: http://www.gutpathogens.com/content///I//2

(c) 2009 Oleastro et al; licensee BioMed Central Ltd.

This is an Open Access article distributed under the terms of the Creative Commons Attribution License (http://creativecommons.org/licenses/by/2.0), which permits unrestricted use, distribution, and reproduction in any medium, provided the original work is properly cited.

\begin{abstract}
Background: homB encodes a Helicobacter pylori outer membrane protein. This gene was previously associated with peptic ulcer disease (PUD) and was shown to induce activation of interleukin-8 secretion in vitro, as well as contributing to bacterial adherence. Its $90 \%$-similar gene, homA, was previously correlated with gastritis. The present study aimed to evaluate the gastric disease association with homB and homA, as well as with the $H$. pylori virulence factors cagA, babA and vacA, in $4 \mathrm{I} 5 \mathrm{H}$. pylori strains isolated from patients from East Asian and Western countries. The correlation among these genotypes was also evaluated.
\end{abstract}

Results: Both homB and homA genes were heterogeneously distributed worldwide, with a marked difference between East Asian and Western strains. In Western strains ( $n=234$, I 24 PUD and I 10 non-ulcer dyspepsia (NUD), homB, cagA and vacA sI were all significantly associated with PUD ( $P$ $=0.025, p=0.014, p=0.039$, respectively $)$, and homA was closely correlated with NUD $(p=0.072)$. In East Asian strains ( $n=138,73$ PUD and 65 NUD), homB was found more frequently than homA, and none of these genes was associated with the clinical outcome.

Overall, homB was associated with the presence of $\operatorname{cag} A(p=0.043)$ and vacA sl $(p<0.00 I)$, whereas homA was found more frequently in cagA-negative $(p=0.062)$ and vacA s2 $(p<0.001)$ strains.

Polymorphisms in homB and homA copy number were observed, with a clear geographical specificity, suggesting an involvement of these genes in host adaptation. A correlation between the homB two-copy genotype and PUD was also observed, emphasizing the role of homB in the virulence of the strain.

Conclusion: The global results suggest that homB and homA contribute to the determination of clinical outcome. 


\section{Background}

Helicobacter pylori colonization of the human stomach is associated with chronic gastritis and an increased risk of peptic ulcer disease (PUD), gastric adenocarcinoma and gastric mucosa-associated lymphoid tissue lymphoma [13]. While some $H$. pylori-infected individuals remain asymptomatic, others develop severe gastric disease. Strain-dependent factors may account for differences in clinical outcome, in particular factors that modulate interactions between $H$. pylori and human gastric cells, such as outer membrane proteins (OMP) [4-6]. Recently, the OMP coding gene hom $B$ was associated with an increased risk of PUD in Portuguese children and young adults (age $<40$ years) [7]. Moreover, in vitro assays showed that HomB contributes to the proinflammatory characteristics of $H$. pylori and is involved in bacterial adherence, these two phenomena being more pronounced when homB is present in two copies in a given strain, compared to one copy only [7]. The homB 90\%-similar gene, designated homA, was found to be associated with non-ulcer dyspepsia (NUD) in that same population [7].

In this study, we investigated gastric disease association with homB and hom $A$, as well as the $H$. pylori virulence factors $c a g A, v a c A$ and $b a b A$, in a panel of $H$. pylori clinical strains isolated from patients from East Asian and Western countries, presenting different gastric diseases, namely NUD and PUD. The correlation between those bacterial factors was also evaluated.

\section{Results}

The presence of homB and hom A in the H. pylori clinical strains was determined by PCR. Table 1 summarizes the characteristics of the study population. PCR products, corresponding to either hom $A$, homB or both genes were obtained for all the 415 strains tested. The presence of both genes in the same genome was detected in 43 strains (10.4\%) (36 PUD strains and 7 NUD strains). These strains were excluded from the analysis related to clinical outcome. Thus, a total of 372 strains were included. They comprised 197 strains isolated from PUD patients $(66.3 \%$ male; $50.3 \pm 14.5$ years) and 175 strains isolated from NUD patients $(53.7 \%$ male; $51.1 \pm 13.4$ years $)$.

\section{Distribution of homB and hom A according to clinical outcome}

The results comparing PUD and NUD strains $(n=372)$ in different countries are presented in Fig. 1. Overall, homB was significantly more prevalent in PUD than in NUD strains (75.9 vs $64.7 \%, \mathrm{p}=0.026, \mathrm{OR}=1.7,95 \% \mathrm{CI}[1.06-$ $2.74]$ ), a trend also observed in Western strains (61.3 vs $46.3 \%, \mathrm{p}=0.025, \mathrm{OR}=1.84,95 \% \mathrm{CI}[1.10-3.10])$. East Asian strains were predominantly homB-positive regardless of the clinical outcome (90.4\% in PUD and $83.1 \%$ in NUD). Considering the analysis by country (Table 2),
homB was associated with PUD in strains from France, Sweden, Brazil and Colombia, although with no statistical significance.

Inversely, the hom $\mathrm{A}$ gene was more prevalent in gastritis than in ulcer strains (35.8 vs $25.8 \%, \mathrm{p}=0.046, \mathrm{OR}=1.61$, 95\%CI [1.06-2.74]), a trend also observed in Western strains (54.6 vs $41.9 \%$ ), though not significant (Fig. 1). The analysis by country revealed that homA was more frequently detected in strains isolated from NUD than from PUD in strains from France, Sweden, Brazil and Colombia, although the difference was not statistically significant (Table 2). Previously, it had been shown that homB was strongly associated with PUD strains isolated from young adults (age < 40 years) [7]. In the present study, a total of 90 strains were isolated from this age group. In this group, homB was significantly associated with PUD (n $=47$, mean age $35.7 \pm 5.8 \mathrm{y}, 47.8 \%$ men) when compared to NUD strains $(\mathrm{n}=43$, mean age $33.4 \pm 5.2 \mathrm{y}, 55.9 \%$ men) (78.7 vs 48.8\%; p $=0.006, \mathrm{OR}=3.88,95 \% \mathrm{CI}$ [1.41-10.84]). When considering only Western strains (31 PUD and 28 NUD), the same association was found (74.2 vs $35.7 \%$; $\mathrm{p}=0.007, \mathrm{OR}=5.18,95 \%$ CI $[1.49-$ 18.68]), but not when East Asian strains only were considered (data not shown).

It was previously demonstrated that homB and homA can be present in a single- or two-copy form within a genome [7]. In the present study, the homB/homA copy number was determined for all 372 strains carrying homB or hom $A$ only. All of the East Asian strains carried the single-copy genotype, and this genotype was also the most frequently found in strains isolated in Portugal (60/100, 60\%), France $(23 / 33,69.7 \%)$, Sweden $(18 / 22,81.8 \%)$, Germany $(15 / 19,78.9 \%)$ and Colombia (11/18, 61.1\%). Due to the high prevalence of the single-copy genotype, no correlation was found between homB/homA copy number and clinical outcome in these populations. Regarding strains isolated in the USA, 52.2\% (12/23) were found to carry the single-copy genotype, while the remaining carried the two-copy genotype, however the distribution of these genotypes was similar among PUD and NUD strains (data not shown). Finally, concerning strains from Brazil, the two-copy genotype was the most frequently detected $(28 / 37,75.8 \%)$, in both PUD and in NUD strains.

When considering the group of strains isolated from Western young adults (age < 40 years, 31 PUD and 28 NUD), a correlation was observed between copy-number of a specific gene and the clinical outcome. Thus, the hom $B$ two-copy genotype was the most frequently observed among PUD strains and the rarest genotype among NUD strains $(38.7 \%$ vs $14.3 \%, \mathrm{p}=0.069)$, while the inverse situation was observed for the homA single-copy genotype 
Table I: Distribution of Helicobacter pylori strains included in the study $(n=415)$, according to geographical origin and disease status of patients.

\begin{tabular}{|c|c|c|c|c|}
\hline Origin & Disease & No. of strains & Gender (\% male) & Median age \pm SD (years) \\
\hline \multicolumn{5}{|c|}{ Western countries } \\
\hline \multirow[t]{4}{*}{ Portugal } & NUD & 50 & 44.7 & $51.3 \pm 14.6$ \\
\hline & DU & 36 & 44.4 & $47.6 \pm 16.6$ \\
\hline & GU & 14 & 76.9 & $54.8 \pm \mid 4.1$ \\
\hline & Total number & 100 & 47.3 & $51.2 \pm 15.1$ \\
\hline \multirow[t]{3}{*}{ France } & NUD & 6 & 100.0 & $38.0 \pm 7.8$ \\
\hline & DU & 28 & 80.0 & $49.3 \pm 14.3$ \\
\hline & Total number & 34 & 82.9 & $47.7 \pm 14.1$ \\
\hline \multirow[t]{3}{*}{ Sweden } & NUD & 10 & 28.6 & $62.1 \pm 6.6$ \\
\hline & DU & 17 & 80.0 & $69.7 \pm 12.9$ \\
\hline & Total number & 27 & 58.8 & $66.6 \pm 11.2$ \\
\hline \multirow[t]{3}{*}{ Germany } & NUD & 10 & 40.0 & $57.3 \pm 11.0$ \\
\hline & DU & 10 & 60.0 & $59.8 \pm 13.3$ \\
\hline & Total number & 20 & 50.0 & $58.6 \pm 11.9$ \\
\hline \multirow[t]{3}{*}{ USA } & NUD & 14 & 57.1 & $41.3 \pm 8.8$ \\
\hline & DU & 15 & 73.3 & $55.6 \pm 10.5$ \\
\hline & Total number & 29 & 67.9 & $48.7 \pm 12.0$ \\
\hline \multirow[t]{3}{*}{ Brazil } & NUD & 18 & 45.0 & $49.3 \pm 13.4$ \\
\hline & DU & 19 & 35.0 & $50.0 \pm 18.8$ \\
\hline & Total number & 37 & 52.4 & $49.7 \pm 15.7$ \\
\hline \multirow[t]{3}{*}{ Colombia } & NUD & 9 & 30.0 & $53.0 \pm 13.6$ \\
\hline & DU & 10 & 88.9 & $46.7 \pm 11.5$ \\
\hline & Total number & 19 & 57.9 & $50.0 \pm 12.7$ \\
\hline
\end{tabular}

East Asian countries

\begin{tabular}{|c|c|c|c|c|}
\hline \multirow[t]{4}{*}{ Japan } & NUD & 28 & 46.7 & $55.8 \pm 16.1$ \\
\hline & DU & 22 & 59.1 & $40.6 \pm 11.5$ \\
\hline & GU & 21 & 76.2 & $54.4 \pm 12.1$ \\
\hline & Total number & 71 & 57.9 & $44.3 \pm 12.7$ \\
\hline \multirow[t]{4}{*}{ South Korea } & NUD & 37 & 79.5 & $46.4 \pm 10.6$ \\
\hline & DU & 29 & 70.8 & $45.8 \pm 11.9$ \\
\hline & GU & 1 & $*$ & - \\
\hline & Total number & 67 & 76.1 & $44.7 \pm 9.9$ \\
\hline \multicolumn{5}{|l|}{ African country } \\
\hline Burkina Faso & DU & 11 & N.A. & N.A. \\
\hline
\end{tabular}

NUD, non-ulcer dyspepsia

DU, duodenal ulcer

GU, gastric ulcer

No., number

N.A. data not available

$* 38$ year old male patient

(NUD vs PUD: $35.7 \%$ vs $9.7 \%, \mathrm{p}=0.036, \mathrm{OR}=5.19$, 95\%CI [1.09-27.87]).

\section{Distribution of cagA, vacA s and babA according to clinical outcome}

Considering all strains and similarly to homB, both cagA and vacA s1 were independently correlated with PUD (78.9 vs 65.0\%, $\mathrm{p}=0.014$, OR $=2.0,95 \%$ CI [1.16-3.47] for $c a g A ; 76.8$ vs $67.1 \%, \mathrm{p}=0.070, \mathrm{OR}=1.6,95 \% \mathrm{CI}$
[0.97-2.70] for vacA), a tendency also observed in Western strains (72.2 vs $54.6 \%, \mathrm{p}=0.014$, OR $=2.2,95 \% \mathrm{CI}$ [1.20-3.86], and 71.0 vs 57.4\%, $\mathrm{p}=0.039, \mathrm{OR}=1.8$, 95\%CI [1.05-3.12], respectively). With regard to $b a b A$, it was only slightly more prevalent in PUD than in gastritis, considering all strains (58.1 vs $54.3 \%$ ), and the Western strains (47.6 vs 40.7\%). East Asian strains were all vacA s1, $c a g A$ and $b a b A$-positive. Considering the analysis by coun- 


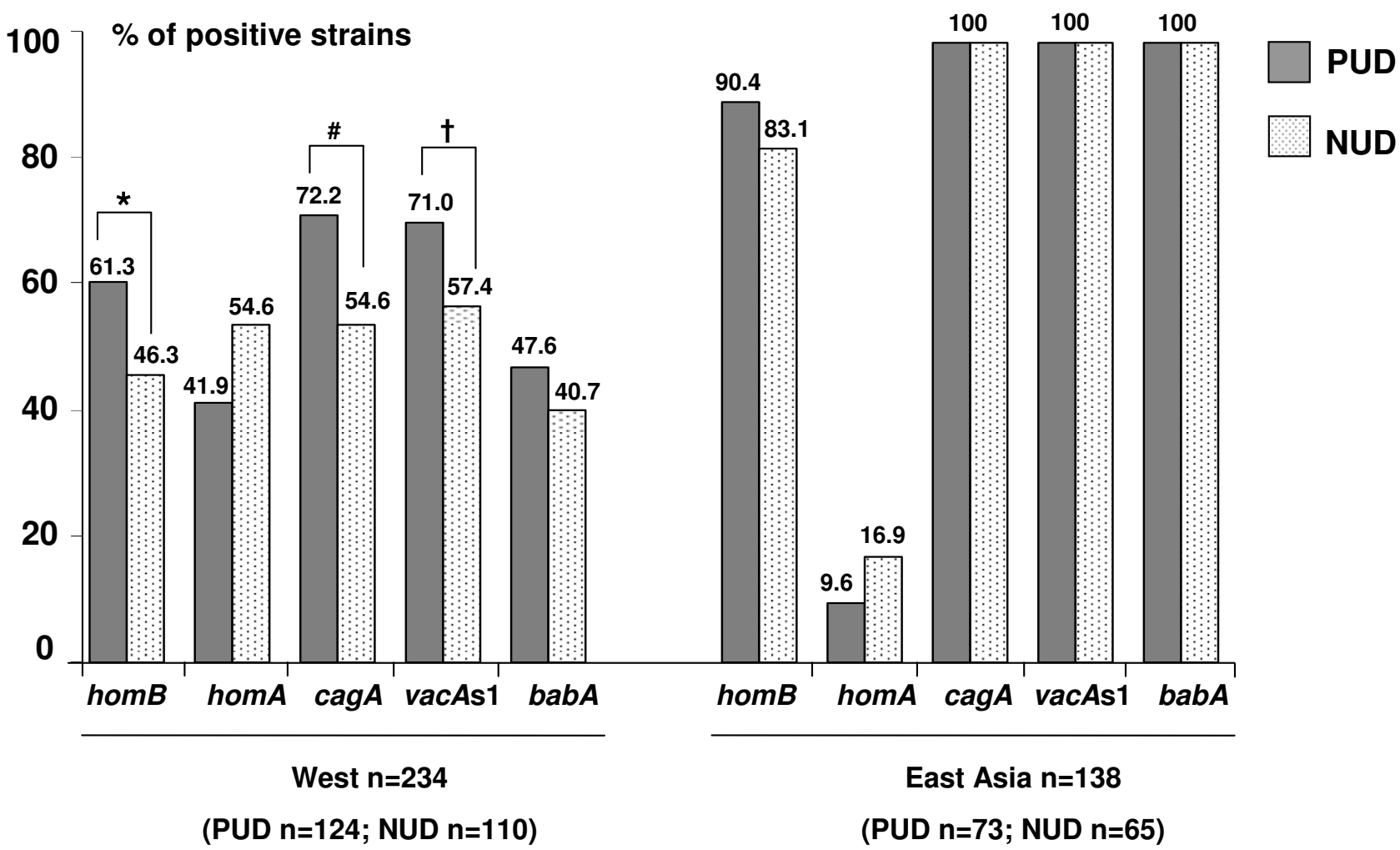

Figure I

Distribution of Helicobacter pylori genotypes among 372 strains isolated from East Asian and Western countries with regard to clinical outcome. PUD (peptic ulcer disease). NUD (non-ulcer dyspepsia). ${ }^{*} \mathrm{p}=0.025 ; \mathrm{OR}=\mathrm{I} .84$, $95 \% \mathrm{Cl}[\mathrm{I} .10-3.10] .{ }^{\#} \mathrm{p}=0.014 ; \mathrm{OR}=2.2,95 \% \mathrm{Cl}[\mathrm{I} .20-3.86] .{ }^{{ }^{t}} \mathrm{p}=0.039 ; \mathrm{OR}=1.8,95 \% \mathrm{Cl}[\mathrm{I} .05-3.12]$.

try, only the cagA-positive genotype was significantly associated with PUD in strains from Portugal (Table 2).

\section{Association of homB and hom A with cagA, vacA s and babA}

The association of homB and hom A with the H. pylori-virulence genotypes $\operatorname{cag} A$, vacA s 1 and $b a b A$ was also evaluated. Considering only the Western strains, the presence of homB was associated with $\operatorname{cag} A(\mathrm{p}=0.043)$ and $v a c A \mathrm{~s} 1$ $(\mathrm{p}<0.001)$, while homA was more frequently found in strains lacking $\operatorname{cag} A(\mathrm{p}=0.062)$ and with the vacA s2 genotype ( $\mathrm{p}<0.001)$. The East Asian strains were all cagApositive, $b a b A$-positive and vacA s1, among which $94.2 \%$ of the Japanese isolates and $78.5 \%$ of Korean strains were also homB-positive.

\section{Discussion}

Using a large panel of $H$. pylori strains $(\mathrm{n}=372)$ isolated from patients from East Asian and Western countries, it was possible to confirm the association of homB with PUD and homA with NUD, previously observed with $H$. pylori strains $(\mathrm{n}=84)$ isolated from Portuguese patients [7]. Considering the distribution according to geographical region, hom B was found to be significantly associated with PUD in strains from Western countries. However, when considering each country individually, only a tendency was observed probably due to the small number of strains tested in each case. The most common H. pylori strain circulating in the East Asia was extremely virulent, harboring hom $B, \operatorname{cag} A$, and $b a b A$ genes and the vacA s1 genotype, regardless of the clinical outcome. Consequently no association with a specific disease was found, confirming the results from previous studies $[8,9]$. Indeed, exposure to risk factors must be heterogeneous to find an association, and this is not the case in Asia. In addition, other environmental factors, e.g. diet, and possibly host genetic factors, may contribute to this evolution [10].

The previously reported significant association of homB with PUD in young adults (age $<40$ years, 32 patients) [7] was confirmed in the present study with a higher number of patients $(\mathrm{n}=90)$.

Polymorphism in copy number of $H$. pylori OMPs may contribute to increase the fitness of the strain and also its virulence $[4,11,12]$. Indeed, the hom $B$ two-copy genotype 
Table 2: Univariate analysis of the relationship between Helicobacter pylori virulence genotypes and clinical outcome according to country, from patients presenting peptic ulcer disease or non-ulcer dyspepsia.

\begin{tabular}{|c|c|c|c|c|c|}
\hline & \multicolumn{5}{|c|}{$\begin{array}{c}\text { Prevalence (\%) PUD vs NUD } \\
\text { p-valuet; OR [ } 95 \% \mathrm{Cl}]\end{array}$} \\
\hline & $\operatorname{hom} B$ & homA & $\operatorname{cag} A$ & $\operatorname{vac} A$ sI & $b a b A$ \\
\hline $\begin{array}{c}\text { Portugal } \\
50 \text { PUD; } 50 \text { NUD }\end{array}$ & $\begin{array}{l}59.6 \text { vs } 56.0 \\
\text { N.S. }\end{array}$ & $\begin{array}{l}40.4 \text { vs } 44.0 \\
\text { N.S. }\end{array}$ & $\begin{array}{c}72.3 \text { vs } 40.0 \\
0.002 ; 1.88[1.26-2.8 I]\end{array}$ & $\begin{array}{l}63.8 \text { vs } 44.0 \\
\text { N.S. }\end{array}$ & $\begin{array}{l}48.9 \text { vs } 32.0 \\
\text { N.S. }\end{array}$ \\
\hline $\begin{array}{c}\text { France } \\
27 \text { PUD; } 6 \text { NUD }\end{array}$ & $\begin{array}{l}\text { 74.I vs } 28.6 \\
\text { N.S. }\end{array}$ & $\begin{array}{l}37.0 \text { vs } 71.4 \\
\text { N.S. }\end{array}$ & $\begin{array}{l}85.2 \text { vs } 60.0 \\
\text { N.S. }\end{array}$ & $\begin{array}{l}85.2 \text { vs } 80.0 \\
\text { N.S. }\end{array}$ & $\begin{array}{l}80.0 \text { vs } 50.0 \\
\text { N.S. }\end{array}$ \\
\hline $\begin{array}{c}\text { Sweden } \\
12 \text { PUD; } 10 \text { NUD }\end{array}$ & $\begin{array}{l}41.7 \text { vs } 30.0 \\
\text { N.S. }\end{array}$ & $\begin{array}{l}58.3 \text { vs } 70 \\
\text { N.S. }\end{array}$ & $\begin{array}{l}83.3 \text { vs } 70.0 \\
\text { N.S. }\end{array}$ & $\begin{array}{l}66.7 \text { vs } 70.0 \\
\text { N.S. }\end{array}$ & $\begin{array}{l}83.3 \text { vs } 40.0 \\
\text { N.S. }\end{array}$ \\
\hline $\begin{array}{c}\text { Germany } \\
9 \text { PUD; } 10 \text { NUD }\end{array}$ & $\begin{array}{l}55.6 \text { vs } 60.0 \\
\text { N.S. }\end{array}$ & $\begin{array}{l}44.4 \text { vs } 40.0 \\
\text { N.S. }\end{array}$ & $\begin{array}{l}100 \text { vs } 80 \\
\text { N.S. }\end{array}$ & $\begin{array}{l}100 \text { vs } 80.0 \\
\text { N.S. }\end{array}$ & $\begin{array}{l}77.8 \text { vs } 60.0 \\
\text { N.S. }\end{array}$ \\
\hline $\begin{array}{c}\text { USA } \\
10 \text { PUD; } 13 \text { NUD }\end{array}$ & $\begin{array}{l}40.0 \text { vs } 33.3 \\
\text { N.S. }\end{array}$ & $\begin{array}{l}60.0 \text { vs } 66.7 \\
\text { N.S. }\end{array}$ & $\begin{array}{l}60.0 \text { vs } 91.7 \\
\text { N.S. }\end{array}$ & $\begin{array}{l}70.0 \text { vs } 91.7 \\
\text { N.S. }\end{array}$ & $\begin{array}{l}100 \text { vs } 91.7 \\
\text { N.S. }\end{array}$ \\
\hline $\begin{array}{c}\text { Brazil } \\
10 \text { PUD; } 12 \text { NUD }\end{array}$ & $\begin{array}{l}70.0 \text { vs } 27.3 \\
\text { N.S. }\end{array}$ & $\begin{array}{l}30.0 \text { vs } 72.7 \\
\text { N.S. }\end{array}$ & $\begin{array}{l}60 \text { vs } 18.2 \\
\text { N.S. }\end{array}$ & $\begin{array}{l}50.0 \text { vs } 27.3 \\
\text { N.S. }\end{array}$ & $\begin{array}{l}100 \text { vs } 100 \\
\text { N.S. }\end{array}$ \\
\hline $\begin{array}{c}\text { Colombia } \\
9 \text { PUD; } 9 \text { NUD }\end{array}$ & $\begin{array}{l}77.8 \text { vs } 60.0 \\
\text { N.S. }\end{array}$ & $\begin{array}{l}33.3 \text { vs } 50.0 \\
\text { N.S. }\end{array}$ & $\begin{array}{l}55.6 \text { vs } 80 \\
\text { N.S. }\end{array}$ & $\begin{array}{l}66.7 \text { vs } 70.0 \\
\text { N.S. }\end{array}$ & $\begin{array}{l}100 \text { vs } 70.0 \\
\text { N.S. }\end{array}$ \\
\hline $\begin{array}{c}\text { Japan } \\
42 \text { PUD; } 28 \text { NUD }\end{array}$ & $\begin{array}{l}95.5 \text { vs } 92.9 \\
\text { N.S. }\end{array}$ & $\begin{array}{l}4.7 \text { vs } 3.6 \\
\text { N.S. }\end{array}$ & $\begin{array}{l}100 \text { vs } 100 \\
\text { N.A }\end{array}$ & $\begin{array}{l}100 \text { vs } 100 \\
\text { N.A }\end{array}$ & $\begin{array}{l}100 \text { vs } 100 \\
\text { N.A }\end{array}$ \\
\hline $\begin{array}{c}\text { South Korea } \\
28 \text { PUD; } 37 \text { NUD }\end{array}$ & $\begin{array}{c}83.3 \text { vs } 73.7 \\
\text { N.S. }\end{array}$ & $\begin{array}{l}16.7 \text { vs } 26.3 \\
\text { N.S. }\end{array}$ & $\begin{array}{c}100 \text { vs } 100 \\
\text { N.A }\end{array}$ & $\begin{array}{l}100 \text { vs } 100 \\
\text { N.A }\end{array}$ & $\begin{array}{l}100 \text { vs } 100 \\
\text { N.A }\end{array}$ \\
\hline
\end{tabular}

Among the 4I5 isolates initially included, 43 (36 PUD strains and 7 NUD) harbored both homA and homB genes and were excluded from further analyses. These 49 isolates comprised all the 1 I isolates from Burkina Faso.

t $\mathrm{p}$-value was determined by the Fisher's Exact Test.

OR, odds ratio.

N.S., not significant.

N.A, not applicable.

PUD, peptic ulcer disease

NUD, non-ulcer dyspepsia

was associated with an increased rate of in vitro interleukin- 8 secretion as well as an increased in vitro adherence [7]. Furthermore, it was the genotype most frequently found in strains from young adults with PUD, while homA single-copy was the most frequent in NUD strains, in agreement with previous data [7]. Globally, these data suggest that in some populations, the severity of $H$. pylori-associated disease in younger subjects may be closely related to the virulence of the strain, irrespective of the contribution of host and/or environmental factors which play a major role in adults. On the other hand, the present study demonstrates that there is a marked geographical specificity regarding homB/homA copy number, particularly evident between East Asian and Western strains, but also amongst Western countries, suggesting that copy number of the homB/homA OMP coding genes also plays a role in adaptation to the human host.

Several $H$. pylori genes encoding OMP display allelic variation, as is the case of $b a b A, b a b B$ [13], hopQ [14] and hopZ [15]. In all of these cases, a conserved profile of gene segmentation is observed, with a variable region which defines the existence of at least two highly conserved allelic variants. Regarding homB and homA, no information on allelic variation is available to date. Further sequence analysis of these coding regions using $H$. pylori strains with different geographical background would allow assessing the existence of allelic variation and to evaluate whether different alleles could be associated with a specific clinical outcome and/or reflect a dissimilar geographical origin.

The cagA-positive and vacA s1 genotypes were independently associated with PUD in Western strains, but not $b a b A$. Previous publications reported a significant association between the presence of $b a b A$ and PUD in Western strains $[16,17]$, contrasting with the present result. This discrepancy may be explained by the very heterogeneous Western study group with regard to the geographical origin of the strains, and also because of a possible absence of PCR amplification due to diversity within babA $[17,18]$.

hom $B$ was found to co-exist with the most virulent genotypes, while homA was more frequently found in strains lacking these genotypes, in agreement with previous results [7]. Thus, it is likely that the phenotype resulting from the expression of cagA, vacA s 1 and homB genes confers a biological advantage to the strain, with the cumulative action of each factor contributing at the same time to the fitness of the strains in vivo and to a more pronounced 
pro-inflammatory response. Another hypothesis would be that homB is linked to PUD only because of its association with other virulence factors. However, its role in $H$. pylori-associated inflammation and in bacterial adherence supports the hypothesis that homB contributes to disease development [7].

Globally, these results suggest that homB and homA seem to be good candidates for the pool of $H$. pylori factors involved in the determination of clinical outcome.

\section{Methods}

\section{Bacterial strains}

A total of $415 \mathrm{H}$. pylori strains isolated from patients from 10 different countries, suffering from NUD ( $\mathrm{n}=182)$, PUD $(\mathrm{n}=233)$, of which 197 duodenal ulcers and 36 gastric ulcers, were included in this study (Table 1). H. pylori strains were cultured from gastric biopsies on agar supplemented with $10 \%$ horse blood, preserved in trypticase soy broth supplemented with $20 \%$ glycerol and maintained at $-80^{\circ} \mathrm{C}$ until used. Genomic DNA was extracted from a 48 h-old culture grown in agar base supplemented with $10 \%$ horse blood, using the QIAamp DNA mini kit (Qiagen GmbH, Hilden, Germany), according to the manufacturer's instructions.

\section{Genotyping of homB, homA, cagA, vacA s and babA by $P C R$ and sequencing}

The homB and homA genes were amplified by a single PCR with a set of primers designed on a consensus internal sequence present in both genes [19]. In order to determine the homB and hom A copy number, primers targeting the respective loci where used, as previously described [19]. The presence of the vacA s allelic variants, s1 and s2, and $\operatorname{cag} A$ and $b a b A$ genes were determined using published PCR primers $[13,16,20,21]$.

\section{Statistical analysis}

Statistical analysis was performed using the statistical software package SPSS (version 14.0; SPSS). The level of significance was set at 5\%, with the null hypothesis rejected when $\mathrm{p}<0.05$.

\section{Abbreviations}

(PUD): Peptic ulcer disease; (GU): gastric ulcer; (DU): duodenal ulcer; (NUD): non-ulcer dyspepsia; (OMP): outer membrane protein; (OR): odds ratio; (CI): confidence interval.

\section{Competing interests}

The authors declare that they have no competing interests.

\section{Authors' contributions}

$\mathrm{MO}$ carried out the experimental design of the study, statistical analysis and co-drafted the manuscript; RC, YY and
DQ carried out bacterial cultures and PCR; FM co-drafted the manuscript; LM supervised the study and AM supervised the study and co-drafted the manuscript. All authors read and approved the final manuscript.

\section{Acknowledgements}

The authors thank Markus Gerhard for supplying $H$. pylori strains from German patients, and Thomas Borén and Lars Engstrand for providing the Swedish strains used in this study. We are grateful to Lindsay Mégraud for careful reading this manuscript.

\section{References}

I. NIH Consensus Development Panel: Helicobacter pylori in peptic ulcer disease. JAMA, ed. NIH Consensus Development Panel on Helicobacter pylori in peptic ulcer disease 1994:65-9.

2. Parsonnet J, Friedman GD, Vandersteen DP, Chang Y, Vogelman JH, Orentreich N, Sibley RK: Helicobacter pylori infection and the risk of gastric carcinoma. N Eng J Med I99|, 325:| | 27-3I.

3. Stolte M, Bayerdörffer E, Morgner A, Alpen B, Wündisch T, Thiede C, Neubauer A: Helicobacter and gastric MALT lymphoma. Gut 2002, 50(Suppl 3): 19-24.

4. Ilver D, Arnqvist A, Ögren J, Frick I-M, Kersulyte D, Incecik ET, Berg DE, Covacci A, Engstrand L, Boren T: Helicobacter pylori adhesin binding fucosylated histo-blood group antigens revealed by retagging. Science 1998, 279:373-7.

5. Mahdavi J, Sonden B, Hurtig M, Olfat FO, Forsberg L, Roche N, Angstrom J, Larsson T, Teneberg S, Karlsson KA, Altraia S, Wadström T, Kersulyte D, Berg DE, Dubois A, Petersson C, Magnusson KE, Norberg T, Lindh F, Lundskog BB, Arnqvist A, Hammarstrom L, Boren T: Helicobacter pylori SabA adhesin in persistent infection and chronic inflammation. Science 2002, 297:573-8.

6. Yamaoka Y, Kikuchi S, El-Zimaity HM, Gutierrez O, Osato MS, Graham DY: Importance of Helicobacter pylori oipA in clinical presentation, gastric inflammation, and mucosal interleukin 8 production. Gastroenterology. 2002, I 23(2):4|4-424.

7. Oleastro M, Cordeiro R, Ferrand J, Nunes B, Lehours P, CarvalhoOliveira I, Mendes AI, Penque D, Monteiro L, Megraud F, Menard A: Evaluation of the clinical significance of hom B, a novel candidate marker of Helicobacter pylori strains associated with peptic ulcer disease. J Infect Dis 2008, 198:1379-87.

8. Maeda S, Ogura K, Yoshida H, Kanai F, Ikenoue T, Kato N, Shiratori Y, Omata M: Major virulence factors, VacA and CagA, are commonly positive in Helicobacter pylori isolates in Japan. Gut 1998, 42:338-43.

9. Mizushima T, Sugiyama T, Komatsu Y, Ishizuka J, Kato M, Asaka M: Clinical relevance of the babA2 genotype of Helicobacter pylori in Japanese clinical isolates. I Clin Microbiol 200I, 39:2463-5.

10. Tsugane S: Salt, salted food intake, and risk of gastric cancer: epidemiologic evidence. Cancer Sci 2005, 96:I-6.

II. Alm RA, Bina J, Andrews BM, Doig P, Hancock RE, Trust TJ: Comparative genomics of Helicobacter pylori: Analysis of the outer membrane protein families. Infect Immun 2000, 68:4155-68.

12. Solnick JV, Hansen LM, Salama NR, Boonjakuakul JK, Syvanen M: Modification of Helicobacter pylori outer membrane protein expression during experimental infection of rhesus macaques. Proc Natl Acad Sci USA 2004, I 1 I:2 106-II.

13. Pride DT, Meinersmann RJ, Blaser MJ: Allelic variation within Helicobacter pylori babA and babB. Infect Immun 200I, 69: ||60-7|.

14. Cao P, Cover TL: Two different families of hopQ alleles in Helicobacter pylori. J Clin Microbiol 2002, 40:4504-II.

15. Peck B, Ortkamp M, Diehl KD, Hundt E, Knapp B: Conservation, localization and expression of HopZ, a protein involved in adhesion of Helicobacter pylori. Nucl Acids Res 1999, 27:3325-33.

16. Gerhard M, Lehn N, Neumayer N, Boren T, Rad R, Schepp W, Miehlke S, Classen M, Prinz C: Clinical relevance of the Helicobacter pylori gene for blood-group antigen-binding adhesin. Proc Nat Acad Sci USA 1999, 96: 12778-83.

17. Olfat FO, Zheng Q, Oleastro M, Voland P, Boren T, Karttunen R, Engstrand L, Rad R, Prinz C, Gerhard M: Correlation of the Helicobacter pylori adherence factor BabA with duodenal ulcer 
disease in four European countries. FEMS Immunol Med Microbiol 2005, 44: I5I-6.

18. Oliveira AG, Santos A, Guerra JB, Rocha GG, Rocha AMC, Oliveira CA, Cabral M, Nogueira A, Queiroz DMM: babA 2- and cagA-positive Helicobacter pylori strains are associated with duodenal ulcer and gastric carcinoma in Brazil. J Clin Microbiol 2003, 4I:3964-6.

19. Oleastro M, Monteiro L, Lehours P, Megraud F, Menard A: Identification of markers for Helicobacter pylori strains isolated from children with peptic ulcer disease by suppressive subtractive hybridization. Infect Immun 2006, 74:4064-74.

20. Atherton JC, Cao P, Peek RM, Tummuru MKR, Blaser MJ, Cover TL: Mosaicism in vacuolating cytotoxin alleles of Helicobacter pylori - Association of specific vacA types with cytotoxin production and peptic ulceration. J Biol Chem 1995, 270: I777|-7.

21. Tummuru MKR, Cover TL, Blaser MJ: Cloning and expression of a high-molecular-mass major antigen of Helicobacter pylori: evidence of linkage to cytotoxin production. Infect Immun 1993, 61:1799-809.

Publish with Bio Med Central and every scientist can read your work free of charge

"BioMed Central will be the most significant development for disseminating the results of biomedical research in our lifetime. "

Sir Paul Nurse, Cancer Research UK

Your research papers will be:

- available free of charge to the entire biomedical community

- peer reviewed and published immediately upon acceptance

- cited in PubMed and archived on PubMed Central

- yours - you keep the copyright

Submit your manuscript here:

http://www.biomedcentral.com/info/publishing_adv.asp 